Мирослав Ясин

\title{
ГЛУХИЕ И СЛАБОСЛЫШАЩИЕ СТУДЕНТЫ В СИСТЕМЕ ИНКЛЮЗИВНОГО ВЫСШЕГО ОБРАЗОВАНИЯ: ВОЗМОЖНОСТИ И БАРЬЕРЫ
}

Статья посвящена проблеме доступности высшего образования для инвалидов по слуху - глухих и слабослышащих людей. Показана ситуация с высшим образованием лиц с потерей слуха до введения инклюзивного образования и те изменения, которые произошли после введения закона об инклюзивном образовании. Эмпирическим материалом послужили результаты фокусированных групповых бесед с глухими и слабослышащими, опросов, экспертных интервью с работниками образования и общественных организаций глухих. Материал анализировался в измерении «возможностей и барьеров». До введения инклюзии образовательные возможности были ограничены по количеству принимающих вузов крайне узким набором специальностей и географически $-85 \%$ мест для обучения были сосредоточены в Москве. Ключевым фактором доступности образования для лиц с потерей слуха выступает наличие перевода образовательного процесса на жестовый язык. После введения инклюзии открылись более широкие возможности для поступления абитуриентов-инвалидов, однако на текущий момент совсем небольшое чисто вузов готово обеспечивать перевод на жестовый язык в ходе получения образования. Для образовательного процесса важную роль играет квалификация переводчиков жестового языка и их специализация, но профессиональная подготовка переводчиков находится пока в начальной стадии. Дополнительными барьерами для глухих и слабослышащих людей являются: низкий уровень школьной подготовки и отсутствие довузовской подготовки; слабое информирование о наборе инвалидов по слуху в вуз; низкие шансы получить работу по специальности, снижающее мотивацию к обучению; неготовность вузов к работе

Мирослав Иванович Ясин-к.с.н., психолог, доцент кафедры управления сестринской деятельностью и социальной работы, Первый московский государственный медицинский университет им. И.М. Сеченова Минздрава России, Москва, Россия. Электронная почта: nadsaw@yandex.ru 
с глухими и непонимание специфики восприятия такими студентами информации. Названные ограничения несут риск создания «формальной» инклюзии, исключающий инвалидов по слуху из практик получения высшего образования. По истечении шести лет законодательного введения инклюзии, ситуация с получением высшего образования глухими и слабослышащими изменилась незначительно и тяготеет к состоянию до введения инклюзивного законодательства.

Ключевые слова: инклюзивное образование, глухие и слабослышащие люди, потеря слуха, инвалиды, доступность, барьеры

DOI: 10.17323/727-0634-2019-17-4-601-614

В 2012 г. в российском законодательстве произошли существенные изменения, обязывающие все образовательные организации создавать доступную среду, приспособленную к специальным потребностям лиц с ограниченными возможностями здоровья и инвалидностью (Федеральный закон 2012а; Указ Президента 2012). На 2017 г. среди молодежи насчитывалось порядка $12 \%$ студентов, но только 3,07\% инвалидов в возрасте до 30 лет поступали в вузы (Курбангалеева, Веретенников 2017). В 2017 г. в закон внесены поправки, упрощающие процедуру поступления в вузы для инвалидов. Введенная законодательно $10 \%$ квота для инвалидов на обучение в колледжах и вузах призвана выровнять процент студентов из числа инвалидов и условно здоровых. Несмотря на законодательное введение инклюзии в вузах еще в 2012 г., процент студентов-инвалидов к 2017 г. составил всего 0,46\% (Аржаных 2017). Законодательное регулирование инклюзии необходимо, однако формальная доступность высшего образования расходится с реальностью.

Среди людей с нарушениями слуха особую социальную группу составляют те, кто предпочитает жестовый язык как средство коммуникации. Объединенные собственным языком, жестовым языком глухих, но изолированные от многих сфер жизни общества, они сформировали групповую социокультурную специфику (Астахова, Большаков 2017; Базоев, Паленый 2002). Степень потери слуха у слабослышащих людей может быть различной: от небольшой, при которой недостаток слуха полностью компенсирует слуховой аппарат, до значительной, при которой слуховой аппарат не способен обеспечить разборчивость устной речи. В последнем случае, как правило, слабослышащие люди пользуются жестовым языком для коммуникации и в формальном контексте идентифицируют себя как «глухие», особенно если речь идет об адаптации в учебном процессе.

Основным барьером на пути к интеграции в общество для глухих и слабослышащих является языковой барьер, который наиболее четко проявляется в сфере межличностной коммуникации и доступа к информации. Глухие в мире слышащих - «лингвистическое меньшинство», 
которое подвергается дискриминации, особенно остро проявляясь в сфере образования (Skutnabb-Kangas 2008). Равный доступ к информации coставляет важную проблему инвалидов по слуху, согласно заявлениям самого сообщества. Образовательный процесс построен на обмене информацией и постоянной коммуникации, поэтому в данной сфере проблема выступает наиболее рельефно.

Степень потери слуха может быть различной, но среди самих глухих и слабослышащих людей сложился функциональный критерий, который четко разделяет «глухих» и «слышащих» по важной для коммуникации особенности: может ли человек более-менее свободно разбирать устную речь без артикуляционной (визуальной) подсказки. «Если по телефону может разговаривать-значит сльшщащий),- такая демаркация распространена в сообществе глухих и слабослышащих. Именно этот критерий создает очевидную границу между теми, кто может получать образование на общих основаниях, пользуясь техническими средствами адаптации (слуховой аппарат, индукционная петля или иная звукоусиливающая аппаратура) и теми, кому для успешной интеграции в учебную жизнь необходим перевод на жестовый язык. Далее мы будем называть «глухими» всех, кому необходим перевод на жестовый язык для доступа к устной информации, это обозначение соответствует самоидентификации. Наше исследование касается лиц с высокой степенью потери слуха, для которых жестовый язык является предпочтительным средством получения информации в учебном процессе.

Из этого также следует, что главное средство адаптации образовательного процесса к потребностям глухих людей- перевод на жестовый язык. Только это средство обеспечивает равный доступ к образовательным услугам. Без живого «слушания» лекций на жестовом языке, участия в семинарских занятиях, обмена информацией с сокурсниками в ходе выполнения учебных заданий, падает качество образования. Между тем, общие положения указанных выше законов детализируются в «дорожных картах» инклюзивного образования, где обозначаются средства реабилитации, которыми располагает учебное учреждение. Так, в документах инклюзивных вузов, согласно выборочному просмотру десяти вузов, указаны: «звукоусиливающая аппаратура», «акустическая система», «информационная индукционная система». Все это может помочь слышащим речь в слуховом аппарате- «слышащим», согласно терминологии самих людей с потерей слуха. Перевод на жестовый язык в списке реабилитационных средств не обозначен ни в «картах» вузов, ни на главном российском ресурсе инклюзивного образования - Портале инклюзивного образования.

Удастся ли российским вузам полноценно включить в образовательный процесс глухих и слабослышащих людей или реальные обучающие практики останутся в отрыве от формальной обеспеченности данной группы «равным доступом»? Анализ возможных перспектив инклюзивного образования и барьеров на этом пути является целью статьи. 
В исследовании обобщаются материалы, полученные в ходе работы в 2015-2018 гг. Эмпирический материал составляют данные, полученные в результате: анализа официальной статистики и информации из открытых источников; анкетных письменных (127 человек) и личных на жестовом языке опросов глухих и слабослышащих людей, проведенных в 20152016 гг; фокусированных групповых интервью, проведенных с переводом на жестовый язык, с глухими и слабослышащими студентами и выпускниками вузов (две группы, 14 и 15 человек), закончившими учиться в последние 5 лет, проведенных в 2017 г;; экспертных интервью с переводчиками жестового языка (8 человек), педагогами вузов, работающих с группами глухих и слабослышащих студентов (3 человека), сотрудниками отделов вузов по работе с инвалидами в вузах и членами приемных комиссий вузов (4 человека), экспертами из Всероссийского общества глухих, ВОГ (3 человека), экспертом Всемирной федерации глухих по образованию глухих, проведенные в 2017-2018 гг.

\section{Ситуация накануне инклюзии}

В России есть шесть вузов, которые имеют многолетнюю традицию подготовки глухих и слабослышащих лиц: Новосибирский государственный технический университет (НГТУ), Педагогический университет имени А.И. Герцена (РГПУ им. Герцена, Санкт-Петербург), Московский педагогический государственный университет (МПГУ), Российская государственная специализированная академия искусств (РГСАИ, Москва), Московский государственный технический университет имени Н.Э. Баумана (МГТУ им. Баумана) и Российский государственный социальный университет (РГСУ, Москва). В этих учебных заведениях уже много лет набираются группы глухих студентов, разработаны специальные программы, производится перевод аудиторных занятий на жестовый язык.

Специальной статистики по уровню образования или распределению по возрастам глухих и слабослышащих граждан не ведется. По набору студентов в этих шести вузах можно оценить обеспеченность местами глухих до внедрения инклюзии. Так, в 2017 г. выделено порядка 370 мест для этой категории абитуриентов. Однако если подсчитать обеспеченность бюджетными учебными местами россиян до 18 лет и глухих и слабослышащих, показатели для общей выборки составят 0,0096, а для глухих и слабослышащих абитуриентов - 0,0016 (Российское образование 2019). Видно, что до внедрения инклюзивной формы образования обеспеченность глухих учебными местами в вузе была в шесть раз ниже, чем слышащих. Эти цифры приведены без учета коммерческого образования, которые увеличивают количество мест для слышащих в 2-2,5 раза.

Еще одна проблема «доинклюзивного» периода - географическое распределение мест обучения для инвалидов по слуху. Четыре из шести 
вузов находятся в Москве, в 2017 г. в МГТУ имени Баумана выделено 42\% мест, РГСАИ - 21,7\%, РГСУ - 10,8\%, МПГУ - 10,8\% от общего числа мест (370) по России. Еще 10\% мест выделяется в Новосибирские и 4,6\% в СанктПетербурге. Соответственно, Москва аккумулировала в себе 85 \% учебных мест, а за ее пределами остались огромные российские просторы с весьма скромным количеством мест для образования глухих людей. Такое распределение делало образование труднодоступным для студентов из регионов, а разница стоимости уровня жизни между столицей и провинциями создавала для них дополнительный барьер.

Следующий барьер лежал в сфере профессионального выбора. Инвалидам по слуху профессиональное самоопределение ограничено: глухим абитуриентам предлагался скромный список направлений подготовки (Ясин 2016): несколько инженерных специальностей, программирование, социальная работа, сурдопедагогика, художественное, дизайнерское образование и актерское мастерство. Профессиональные мечты у глухих разнообразны, однако наши респонденты из семей глухих вспоминали, что рано были вынуждены понять: им придется отказаться от собственных предпочтений и выбирать из имеющихся специальностей. Респонденты из семей слышащих дольше не осознавали ограничений, но начинали сталкиваться с барьерами на стадии поступления или во время обучения понимали, что не могут учиться на очном отделении без переводчика. До внедрения инклюзии небольшая часть глухих выбирала обучение на общих основаниях, но они не получали специальных адаптационных средств, и обучение сводилось к самообразованию.

Таким образом, основные ограничения «доинклюзивного» периода: крайне небольшое количество мест для инвалидов по слуху в специализированных учебных группах в шести перечисленных вузах; сосредоточенность большей части этих мест в Москве; ограниченный выбор направлений подготовки. Инклюзивное обучение в свою очередь предполагает, что инвалид может поступить в любой вуз, где ему предоставят специальные условия для компенсации физических ограничений.

\section{Стало ли образование более доступным для глухих студентов?}

Опросы показали, что сообщество глухих и слабослышащих к самой идее инклюзии на уровне колледжа и вуза относятся положительно. Посчитали, что она нужна на уровне высшего образования 81,11 \% респондентов, на уровне среднего профессионального образования - 75,36\% (онлайн опрос, 127 респондентов, 2015 г.). В ответах на открытые вопросы поясняется, что инклюзия дает «большой выбор», «доступность: получить желаемую для инвалидов специальность», «должна быть, человек должен иметь выбор профессии». То есть потребность в инклюзии в первую 
очередь связывается респондентами с расширением ассортимента направлений подготовки.

Что касается экспертов, они единогласно утверждают, что новое законодательство прогрессивно, оно дает возможность глухим людям поступать в любой вуз по своему усмотрению, открывая иные профессиональные возможности. Однако говорить о реальных улучшениях ситуации с образованием глухих людей многие эксперты посчитали преждевременным. Законодательно инклюзия в образовании инициирована в 2012 г., по факту ситуация с высшим образованием инвалидов по слуху за прошедшие шесть лет изменилась незначительно.

Согласно результатам фокус-групп, большая часть глухих людей уверена, что поступать можно только в те вузы, которые традиционно предоставляют услуги перевода. Для них наличие перевода на жестовый язык- основное условие при выборе вуза. Некоторые участники фокусгрупп выбрали «инклюзивные» вузы, однако не получали там услуг перевода в ходе учебного процесса. Их образование либо было заочным, либо стало таковым фактически: глухой студент не слышит педагога и имеет дело только с конспектами других студентов и литературой: «Я вообще ничего не слыпу. Я фотографировала их лекции, а потом читала дома» (женщина, 26 лет). Часто студенты, ссылаясь на глухоту, договариваются с преподавателем об индивидуальных домашних заданиях и в дальнейшем не посещают университет. В некоторых вузах заставляют посещать занятия, хотя перевод на жестовый язык не осуществляется, соответственно, у студента нет доступа к информации. В семьях, где родители слышащие, но владеют жестовым языком, часто выполняют роль переводчиков для студента. Образовательный процесс в этом случае полностью копирует положение дел до инклюзивного законодательства, когда глухие люди поступали на общих основаниях и дальше сами справлялись без специальных адаптационных средств.

Перевод на жестовый язык гипотетически предусмотрен п.2.3 Письма Минобрнауки № 06-281 (2014), однако ни одному из наших респондентов, обучавшихся инклюзивно, вуз не предоставил переводчика. В одном случае целой группе глухих и слабослышащих студентов пояснили (со слов респондентки, 36 лет): «Вы же живете в мире слышащуих? Учитесь обходится без переводчика. Как же потом работать будете?». В другом случае респондентку переадресовали с этим вопросом в городское отделение Всероссийского общества глухих, а это общественная организация, которая не занимается обеспечением учебного процесса переводчиками. Несколько респондентов ответили, что использовали свои 40 часов перевода, положенных по индивидуальной программе реабилитации, на перевод лекций, что ничтожно мало, учитывая объем аудиторных занятий. Респонденты отмечали, что «сами ищем выход из ситуащии», «если несколько человек-иногда скидываемся на переводчика». Очевидный факт, 
что глухой человек не может получать информацию через устную речь, и имеет равный доступ к образованию только при наличии перевода, некоторыми вузами явно игнорируется.

Представители приемных комиссий говорят: «Mbl обязаны братьвозьмем», но многие уклоняются от ответа на вопрос, сможет ли вуз предоставить перевод. В одной из комиссий ответили, что принимают абитуриентов «с легкими формами инвалидности»- то есть тех, кто заполнит квоту, но способен справляться без дополнительных адаптационных средств. Имеется довольно большой процент вузов, обращаясь в приемные комиссии которых, инвалид по слуху не получает уверенности в том, что переводчик будет предоставлен. Новый закон об образовании открыл глухим «возможность поступать в любой вуз. А дальше нужно ходить и самостоятельно добиваться, чтобь дали переводчика»- очень верно отражает ситуацию высказывание руководителя лаборатории жестового языка Института социальных технологий и реабилитации Новосибирского государственного технического университета. Согласно экспертной оценке Президента «Объединения переводчиков жестового языка», в последние несколько лет стало увеличиваться число вузов, которые берут в штат переводчиков жестового языка, но это единичные вузы. Список московских вузов с переводчиком на 2018/19 учебный год пополнился на три учебных заведения. Новые инклюзивные вузы принимают на обучение от одного до пяти студентов, чаще одного или двух, по данным Всероссийского общества глухих.

После принятия закона необходима большая работа по разработке подзаконных нормативных актов и их изменению, чтобы инвалиды по слуху могли беспрепятственно получать услуги перевода в образовании, отметил вице-президент Всероссийского общества глухих. В нашем исследовании выявлено, что у вузов есть возможности избегать обеспечения глухих студентов услугами перевода. Так, «статус переводчика жестового языка в вузе не определен», это влечет за собой «отсутствие стандартов норм труда и оплаты труда»,- отмечает эксперт, переводчик из МГТУ им. Баумана. В законах, касающихся жестового языка и перевода в образовании, обозначена «рамка», но нет конкретики- документов, в которых четко указано, в каких случаях, сколько и из каких средств обеспечивается перевод. Вопрос о переводчиках является ключевым для полноценной инклюзии глухих студентов. Однозначно о перспективах инклюзии высказалась эксперт Всемирного общества глухих: «Будет перевод-будет нормальное образование, а без него ничего не получится».

Еще одна проблема, на которую часто обращали внимание эксперты,квалификация переводчиков жестового языка. Программа подготовки переводчиков жестового языка на уровне вуза появилась в России в 2012 г., одновременно с приятием «закона о жестовом языке» (Федеральный закон 2012а) и началом государственной программы по стимулированию интеграции инвалидов. Всего два вуза в стране готовят переводчиков по программам 
полного высшего образования (бакалавриат). Ежегодно они выпускают порядка 20-25 человек, что ничтожно мало в масштабах страны. Проблема острой нехватки переводчиков жестового языка поднималась неоднократно (Ларионов 2014; Варинова, Траулько 2011). Остальные переводчики жестового языка овладевали языком в семье или самостоятельно, затем проходили курсы профессиональной переподготовки. Высококвалифицированные переводчики имеют специализацию, но не всегда готовы переводить образовательный процесс. Для его перевода требуется знание специальной лексики и понимание предмета.

На заре инклюзивного образования существовала специализация вузов по нозологиям, с которыми они готовы были работать (Ярская-Смирнова, Романов 2005). Для глухих и слабослышащих абитуриентов формальная доступность значительно возросла- все вузы считаются инклюзивными и обязаны принимать инвалидов, но реальная ситуация изменилась незначительно - в данный момент немногие вузы готовы обеспечить образовательный процесс переводом на жестовый язык. Дополнительную сложность составляет поиск квалифицированных переводчиков. Предоставление равного доступа к образованию в настоящее время- инициатива отдельных прогрессивных вузов. Студенту приходится «добиваться» того, что ему законодательно положено или платить за перевод самостоятельно. А пока нет гарантий, что перевод будет получен, глухие абитуриенты по большей части стремятся поступать в «проверенные» вузы.

\section{Другие барьеры}

Недостаток информациии. Для абитуриентов с инвалидностью по слуху выбор дополнительно ограничен элементарным отсутствием информации о вузах и условиях обучения. Только $14 \%$ вузов размещают информацию об условиях поступления инвалидов на своем сайте. Портал инклюзивного образования не содержит ключевой для глухого человека информациио предоставлении перевода. Согласно нашим данным, глухие абитуриенты в поиске информации о вузе используют в основном три источника: (1) отзывы друзей и знакомых, информацию, предаваемую в «мире глухих»; (2) специализированные СМИ глухих (например, сайт voginfo.ru); (3) информацию, рассылаемую по школам для глухих. Отзывы друзей и знакомых транслируют по большей части старую информацию о том, где «кода-то кто-то учился». Как правило, это шесть вузов-наследников специализированного образования. Информация, рассылаемая по школам,- фрагментарна: «Нам не предоставили вариантов выбора. Директор просто сказал, что есть педагогический инcmumym» (м. 23 г.). Интернет-сайты глухих наиболее полны, но не детализируют информацию о наличии адаптационных средств в вузе.

Ситуация осложняется, если будущий студент оторван от «мира глухих» и не может получать информацию от сообщества, из специализированных 
СМИ и от знакомых: «Я выросла в семье сльишащих. ... Было мало информаџии, не знали информации, куда мне можно поступить. Вообще были все не в курсе» (ж. 24 г.). Это еще раз подтверждает известный тезис о том, что глухим детям из слышащих семей сложнее адаптироваться, чем их сверстникам из семей глухих (Чаушьян 2014; Базоев, Паленый 2002).

Для глухих абитуриентов ключевыми факторами при выборе вуза, согласно опросам и результатам фокус-групп, являются: (1) наличие переводчика; (2) бюджетные места и стипендии; (3) для иногородних-наличие общежития. Именно эту информацию, а также условия поступления (включая список документов) мы рекомендуем размещать на порталах вузов, осуществляющих инклюзию.

Проблема школьного образования. Большинство экспертов отмечают, что основной проблемой инклюзии глухих в вузах является недостаток школьных знаний, низкий уровень школьной подготовки. А для вузов, где имеются группы глухих - уровень подготовки поступивших. О проблемах школьного образования писалось неоднократно (Чаушьян 2014; Комарова 2006; Базоев, Паленый 2002). Шесть вузов, занимающихся подготовкой глухих студентов, имеют свои пути решения этой проблемынапример, пролонгированный (адаптационный) первый курс в МГТУ им. Баумана, дополнительные занятия в НГТУ, адаптированные программы по общеобразовательным предметам в РГСАИ.

Глухие студенты реже рефлексируют эту проблему. Они перекладывают ответственность за «наверстывание» имеющихся пробелов на вуз, считая, что он должен обеспечить им хорошее понимание программы. Исключение составляют студенты из семей слышащих, которые учились в вузах на общих основаниях. У них складывается гораздо более отчетливое представление о своих учебных компетенциях, и они склонны критически относится к уровню полученных в школе знаний. Более половины респондентов фокус-групп отметили, что глухому человеку в вузе учиться труднее, соответственно, если есть цель получить образование, нужно работать больше, чем слышащему студенту.

На фокус-группе респонденты подняли вопрос о подготовке абитуриентов к вузу. Существуют много курсов подготовки к ЕГЭ для слышащих, но для глухих таких курсов, по словам респондентов, нет. Только в 2017/18 г. запущен всероссийский дистанционный курс по математике, он разрабатывался совместно несколькими вузами при поддержке фонда В. Потанина.

Связь образования и трудоустройства. Проблема трудоустройства в сообществе глухих - одна из самых острых. Глухие люди испытывают трудности с получением работы, особенно это касается престижных и хорошо оплачиваемых мест. Основной причиной проблем с получением места, глухие указывают непонимание слышащими глухих, отвержение, и явное предпочтение слышащими работодателями слышащих сотрудников. Отсутствие возможности получить хорошую работу демотивирует 
молодежь с потерей слуха в плане получения высшего образования. По отзывам и респондентов и экспертов, вопросы, есть ли в вузе практика или распределение по местам, где потом можно работать,- интересуют глухих студентов гораздо больше, чем условно-здоровых. Рассматривая профиль подготовки, глухие абитуриенты обязательно интересуются - а возможно ли потом работать по данной специальности человеку с нарушением слуха? По этой же причине глухие люди не поступают на коммерческое обучение, так как трудности трудоустройством приводят к тому, что они не надеются в дальнейшем окупить семейные расходы на образование, и образование не рассматривается как выгодная инвестиция.

Из 12 выпускников МГПУ 2017 г. с нарушениями слуха лишь двое высказали уверенность, что смогут найти работу по специальности, причем эти двое оказались иностранными студентами. Остальные десять смотрят на устройство на работу по специальности пессимистически (личный опрос 2017 г.). В то же время слышащие выпускники-педагоги стопроцентно уверены, что им найдется место в школе. В обсуждении на фокус-группах мнения распределились: часть участников опиралась на «стандартный» список профессий для глухих, другая видела еще не раскрытые возможности профессиональной самореализации.

Экспертные оценки разделились на те, в которых интервьюируемые утверждали, что образование ценно само по себе, образование расширяет возможности, и те, в которых явно прослеживалась связь перспектив дальнейшего трудоустройства и мотивации к обучению. Стремление к высшему образованию связано с поиском хорошей работы, и проблему повышения уровня образования инвалидов можно рассматривать только в комплексе с решением вопроса о трудовой инклюзии.

Непонимание педагогами специфики глухого студента. Большинство наших респондентов отметили, что в вузах, где не было традиции обучения глухих студентов, педагоги плохо представляют специфику преподавания и допускают множество коммуникативных ошибок, которые затрудняют получение информации студентом. Глухие студенты, обучающиеся на общих основаниях (без переводчика), предпочитают получать конспекты лекции и список литературы до начала занятия, а на занятии «улавливать» общий смысл лекции по артикуляции преподавателя или конспекту соседа по парте. Этот значительно «урезанный» вариант слушания лекций практикуется по причине отсутствия альтернатив- при отсутствии переводчика, образование автоматически превращается в заочное.

Незнание технологий работы с инвалидами и связанная с этим неуверенность - главные проблемы, о которой говорили педагоги всех уровней образования при введении инклюзии (Кошелева 2016). Наш опрос на курсах повышения квалификации (43 человек) показал, что преподаватели в целом позитивно относятся к перспективе увидеть глухого студента в группе, однако большинство (37 человек) не смогли указать ни особых образова- 
тельных потребностей, ни адаптационных средств, помимо слухового аппарата и «чтения по губам». Последнее в значительной мере является заблуждением: слышащие люди уверенны, что по губам возможно «считать» развернутый рассказ, однако, даже при высоких навыках чтения с губ, эффективность порядка 60-70\% полученной информации считается высокой (Chung at al. 2017). Информационные пробелы и иллюзии показывают слабый уровень представлений «здорового» сообщества о жизни инвалидов, то есть отсутствие опыта социальной инклюзии.

Некоторые эксперты пояснили, что в вузах, поддерживающих традицию подготовки глухих людей, имеются научно-обоснованные и отработанные методы и технологии, которые не так-то просто «поставить» в вузе, не имевшем опыта работы с инвалидами по слуху.

\section{Выводы}

Прошло семь лет со времени законодательного внедрения инклюзивного образования инвалидов в России, однако решение проблем разных нозологических групп единым административным средством пока не привело к равному доступу к образованию. Для преодоления низкой вовлеченности инвалидов в образовательный процесс в целом, в 2017 г. приняты дополнительные законодательные меры: введена $10 \%$ квота в вузах и упрощен порядок поступления.

Согласно полученным нами результатам, в высшем образовании глухих инклюзия позволяет преодолеть следующие ограничения. Во-первых, географическую неравномерность распределения вузов, принимающих для образования глухих и слабослышащих студентов. С введением инклюзии глухие абитуриенты могут поступать в любые вузы страны, что повышает географическую доступность. Во-вторых, инклюзивное обучение позволяет значительно расширить перечень направлений подготовки, на которые поступают глухие абитуриенты, что повысит возможности профессионального самоопределения и самореализации.

Ситуация с получением высшего образования инвалидами по слуху меняется медленно, относительно заметные сдвиги начали происходить только в последние два года. Остается ряд барьеров на пути получения высшего образования глухими людьми. Во многих вузах инклюзия производится формально, перевод на жестовый язык не предоставляется. Не теряет остроты проблема нехватки переводчиков и качества перевода- она наиболее значима при получении образования глухими студентами. Существует риск того, что многие вузы будут избегать различными способами обеспечения перевода на жестовый язык образовательного процесса или под разными предлогами откажутся принимать глухих студентов.

Остаются актуальными проблемы школьного образования глухих, которые ведут к низкому уровню знаний и трудностям как на стадии пос- 
тупления в вузы, так и в начале обучения. Дополнительная довузовская подготовка практически отсутствует. Есть проблемы с трудоустройством, которые делают получение образования экономически бессмысленным, следовательно, снижают мотивацию абитуриентов. Неготовность преподавателей вузов к обучению глухих студентов остается высокой, но может быть преодолена при помощи дополнительного обучения профессорскопреподавательского состава и заимствования методологии вузов, имеющих традиции в сфере образования глухих.

Законодательство об инклюзивном образовании должно выступать гарантом равного доступа к образованию, однако на данный момент в нем еще не устранены пробелы и противоречия. Сможет ли инклюзия, как форма образования, обеспечить доступность для всех категорий инвалидов, зависит от того, насколько полно принципы включения будут реализованы на местах.

\section{Список источников}

Аржаных Е.В. (2017) Высшее профессиональное образование для лиц с ограниченными возможностями здоровья и инвалидностью: статистический анализ. Психологическая наука и образование, 22 (1): 150-160.

Астахова Н.В., Большаков Н.В. (2017) Паттерны культурного потребления глухих и слабослышащих: инклюзия или изоляция? Журнал исследований соииальной политики, 15 (1): $51-66$.

Базоев В. З., Паленый В. А. (2002) Человек из мира тишины. М.: Академкнига.

Варинова О.А., Траулько Е.В. (2011) Сурдоперевод как необходимое условие качественного профессионального образования лиц с нарушением слуха. Современные исследования сочиальных проблем, 6 (2):21-23.

Комарова А. А. (2006) Особенности сообществ глухих. А. А. Комарова (ред.) Современные аспекты жестового языка. М.: ВТИИ: 120-129.

Кошелева А. Д. (2016) «Инклюзивное образование»: образование или социализация? Заметки к дискуссии. Новая наука: от идеи к результату, 2-2 (66): 80-85.

Курбангалеева Е.Ш., Веретенников Д.Н. (2017) Доступность высшего профессионального образования инвалидам и лицам с ограниченными возможностями здоровья (OB3). Психологическая наука и образование, 22 (1): 169-180.

Ларионов М. (2014) О жестовом языке, сурдопереводчиках и не только... А. А. Комарова (ред.) За жестовый язык. М.: ВОГ: 33-38.

Письмо Минобрнауки России (2014) О направлении Требований № 06-281 от 18.03.2014. Федеральный закон (2012) О внесении изменений в статьи 14 и 19 Федерального закона «О соииальной защите инвалидов в Российской Федерации» № 296-ФЗ от 30.12.2012.

Чаушьян Н. (2014) Право на жестовый язык. А. А. Комарова (ред.) За жестовый язык. М.: ВОГ: $156-162$.

Ярская-Смирнова Е.Р., Романов П.В. (2005) Доступность высшего образования для инвалидов. Университетское управление: практика и анализ, (1): 89-99.

Ясин М.И. (2016) Отношение глухих и слабослышащих к инклюзивному образованию. Современное образование, (3): 94-100.

Chung J. S., Senior A., Vinyals O., Zisserman A. (2017) Lip Reading Sentences in the Wild. IEEE Conference on Computer Vision and Pattern Recognition (CVPR). Honolulu: Hawaii:3444-3453. Skutnabb-Kangas T. (2008) Human Rights and Language Policy in Education. In: S. May, N. Hornberger (eds.) Language Policy and Political Issues in Education, Volume 1 of Encyclopedia of Language and Education. New York: Springer: 107-119. 
Miroslav Yasin

\section{THE DEAF AND THE HARD OF HEARING IN THE SYSTEM OF INCLUSIVE EDUCATION: OPPORTUNITIES AND BARRIERS}

The article examines the problem of accessibility in higher education for people with hearing loss: the deaf and the hard-of-hearing. The article examines the higher education situation for the deaf prior to the introduction of inclusive education and those changes that occurred after the introduction of the law on inclusive education. The following empirical material was used: the results of focus group interviews with the deaf, polls, expert interviews with employees in education and public organizations for the deaf. The material was analyzed in line with the concept of 'opportunities and barriers'. Prior to the introduction of the inclusion legislation, educational opportunities were limited by the number of host universities, a narrow set of specialties and geographical factors. The key factor in the accessibility of education for the deaf is the availability of sign language interpretation in the educational process. After the introduction of inclusivist legislation, more opportunities for the entry of disabled applicants have appeared, although, at the current moment, only a few higher education institutions are ready to provide sign language interpretation. The training of sign language interpreters and their specialization play an important role in the educational process, even if the professional training of interpreters is still in the initial stages. Additional barriers for the deaf include low levels of school education, the lack of preuniversity training system, a poor system of information sharing with regards university recruitment for people with hearing loss, low chances of finding a job according to one's specialization, which reduces the motivation to study, and the inability of university professors to work with the deaf. These barriers run the risk of creating a merely 'formal' inclusion that, in reality, excludes persons with hearing impairment from higher education. Six years after the introduction of inclusivist legislation, it can be concluded that the situation in higher education for the deaf has not significantly changed.

Key words: inclusive education, deaf and hard of hearing, hearing loss, disabled, accessibility, barriers

DOI: 10.17323/727-0634-2019-17-4-601-614

\section{References}

Arzhanyh E.V. (2017) Vysshee professional'noe obrazovanie dlya lic s ogranichennymi vozmozhnostyami zdorov'ya i invalidnost'yu: statisticheskij analiz [Higher Professional Education for Persons with Disabilities: Statistical Analysis]. Psihologicheskaya nauka i obrazovanie [Psychological Science and Education], 22 (1): 150-160.

Miroslav I. Yasin- PhD in Sociology, Psychologist, Associate Professor of Department of Nursing Management and Social Work, First Moscow State Medical University (Sechenov University), Moscow, Russian Federation. Email: nadsaw@yandex.ru 
Astahova N.V., Bol'shakov N.V. (2017) Patterny kul'turnogo potrebleniya gluhih i slaboslyshashchih: inklyuziya ili izolyaciya? [Cultural Consumption Patterns among the Deaf and Hard of Hearing: Inclusion versus Exclusion]. Zurnal issledovaniy social'noj politiki [The Journal of Social Policy Studies], 15 (1):51-66.

Bazoev V.Z., Palenyj V. A. (2002) Chelovek iz mira tishiny [The Man from the World of Silence]. Moscow: Akademkniga.

Chaush'yan N. (2014) Pravo na zhestovyj yazyk [The Right to Sign Language]. In: A. A. Komarova (ed.) Za zhestovyj yazyk [For Sign Language]. Moscow: VOG: 156-162.

Chung J. S., Senior A., Vinyals O., Zisserman A. (2017) Lip Reading Sentences in the Wild. IEEE Conference on Computer Vision and Pattern Recognition (CVPR). Honolulu: Hawaii: 3444-3453.

Federal Law (2012) O vnesenii izmenenij v stat'i 14 i 19 Federal'nogo zakona 'O social'noj zashhite invalidov v Rossijskoj Federacii' [On the Amendment of Articles 14 and 19 of the Federal Law 'On Social Protection of the Disabled in the Russian Federation'] N 296-FZ from 30.12.2012.

Komarova A. A. (2006) Osobennosti soobshchestv gluhih [Features of the Deaf Community]. In: A. A. Komarova (ed.) Sovremennye aspekty zhestovogo yazyka [Modern Aspects of Sign Language]. Moscow: VTII: 120-129.

Kosheleva A.D. (2016) 'Inklyuzivnoe obrazovanie': obrazovanie ili socializaciya? ['Inclusive Education': Education or Socialization? Notes to the Discussion]. Zametki k diskussii. Novaya nauka: ot idei k rezul'tatu [New Science: From Idea to Result], 2-2 (66): 80-85.

Kurbangaleeva E.SH., Veretennikov D.N. (2017) Dostupnost' vysshego professional'nogo obrazovaniya invalidam i licam s ogranichennymi vozmozhnostyami zdorov'ya (OVZ) [Accessibility of Higher Professional Education to Persons with Disabilities and Persons with Disabilities]. Psihologicheskaya nauka i obrazovanie [Psychological Science and Education], 22 (1): 169-180.

Larionov M. (2014) O zhestovom yazyke, surdoperevodchikah i ne tol'ko [About Sign Language, Sign Language Interpreters and More...]. In: A. A. Komarova (ed.) Za zhestovyj yazyk [For Sign Language]. Moscow: Izd-vo VOG: 33-38.

Letter from the Russian Ministry of Education (2014) O napravlenii Trebovanij [About the Direction of Requirements] N 06-281 from 18.03.2014.

Skutnabb-Kangas T. (2008) Human Rights and Language Policy in Education. In: S. May, N. Hornberger (eds.) Language Policy and Political Issues in Education, Volume 1. New York: Springer: $107-119$.

Varinova O. A., Traul'ko E.V. (2011) Surdoperevod kak neobhodimoe uslovie kachestvennogo professional'nogo obrazovaniya lic s narusheniem sluha [Sign Language Interpretation as a Necessary Condition for Quality Professional Education of Persons with Hearing Impairment]. Sovremennye issledovaniya social'nyh problem [Modern Research of Social Problems], 6 (2):21-23.

Yarskaya-Smirnova E.R., Romanov P.V. (2005) Dostupnost' vysshego obrazovaniya dlya invalidov [Accessibility of Higher Education for the Disabled] Universitetskoe upravlenie: praktika i analiz [Journal University Management: Practice and Analysis], (1): 89-99.

Yasin M.I. (2016) Otnoshenie gluhih i slaboslyshashchih k inklyuzivnomu obrazovaniyu [Attitudes of the Deaf and Hard of Hearing towards Inclusive Education]. Sovremennoe obrazovanie [Modern Education], (3): 94-100. 